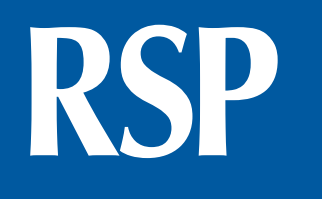

http://www.rsp.fsp.usp.br/
Revista de Saúde Pública

\title{
Fuzzy model to estimate the number of hospitalizations for asthma and pneumonia under the effects of air pollution
}

\author{
Luciano Eustáquio Chaves', ${ }^{\mathrm{III}}$, Luiz Fernando Costa Nascimento ${ }^{\mathrm{III}, \mathrm{IV}}$, Paloma Maria Silva Rocha Rizol ${ }^{\mathrm{V}}$
}

I Departamento de Mecânica. Faculdade de Engenharia de Guaratinguetá. Universidade Estadual Paulista. São Paulo, SP, Brasil

" Fundação Universitária Vida Cristã. Faculdade de Pindamonhangaba. Pindamonhangaba, SP, Brasil

III Departamento de Medicina. Universidade de Taubaté. Taubaté, SP, Brasil

iv Departamento de Energia. Faculdade Engenharia de Guaratinguetá. Universidade Estadual Paulista. Guaratinguetá, SP, Brasil

$\checkmark$ Departamento de Engenharia Elétrica. Faculdade de Engenharia de Guaratinguetá. Universidade Estadual Paulista. Guaratinguetá, SP, Brasil

Correspondence:

Luiz Fernando Costa Nascimento Av Tiradentes, 500 Bom Conselho 12030-180 Taubaté, SP, Brasil

E-mail: luiz.nascimento@pq.cnpq.br

Received: 25 Jun 2015

Approved: 19 Apr 2016

How to cite: Chaves LE Nascimento LFC, Rizol PMSR. Fuzzy model to estimate the number of hospitalizations for asthma and pneumonia under the effects of air pollution. Rev Saude Publica. 2017:51:55.

Copyright: This is an open-access article distributed under the terms of the Creative Commons Attribution License, which permits unrestricted use, distribution, and reproduction in any medium, provided that the original author and source are credited.

\section{ABSTRACT}

OBJECTIVE: Predict the number of hospitalizations for asthma and pneumonia associated with exposure to air pollutants in the city of São José dos Campos, São Paulo State.

METHODS: This is a computational model using fuzzy logic based on Mamdani's inference method. For the fuzzification of the input variables of particulate matter, ozone, sulfur dioxide and apparent temperature, we considered two relevancy functions for each variable with the linguistic approach: good and bad. For the output variable number of hospitalizations for asthma and pneumonia, we considered five relevancy functions: very low, low, medium, high and very high. DATASUS was our source for the number of hospitalizations in the year 2007 and the result provided by the model was correlated with the actual data of hospitalization with lag from zero to two days. The accuracy of the model was estimated by the ROC curve for each pollutant and in those lags.

RESULTS: In the year of 2007, 1,710 hospitalizations by pneumonia and asthma were recorded in São José dos Campos, State of São Paulo, with a daily average of 4.9 hospitalizations (SD = 2.9). The model output data showed positive and significant correlation $(\mathrm{r}=0.38)$ with the actual data; the accuracies evaluated for the model were higher for sulfur dioxide in lag 0 and 2 and for particulate matter in lag 1 .

CONCLUSIONS: Fuzzy modeling proved accurate for the pollutant exposure effects and hospitalization for pneumonia and asthma approach.

DESCRIPTORS: Air Pollution, adverse effects. Asthma, epidemiology. Pneumonia, epidemiology. Hospitalization. Fuzzy Logic. 


\section{INTRODUCTION}

Air pollution is a serious environmental issue, given its impact on human health, especially cardiovascular and respiratory systems ${ }^{1,2}$.

In Brazil, especially in large urban centers, exposure to pollutants like particulate matter $\left(\mathrm{PM}_{10}\right)$, sulfur dioxide $\left(\mathrm{SO}_{2}\right)$, ozone (O3), carbon monoxide (CO) and nitrogen oxides (NOx) is associated with hospitalizations for respiratory diseases such as asthma and pneumonia, thanks to the pollutants easy reach to the respiratory tract ${ }^{3,16}$.

Currently, this issue extends beyond major urban centers ${ }^{7,11}$ and is affecting cities of medium and small size ${ }^{1,6,8}$. Exposure to air pollutants represents the high financial cost for the public network. The cost of 900,000 hospitalizations for pneumonia and asthma in 2011 reached US $\$ 350$ million in Brazil, US\$70 million in São Paulo State, with 150,000 hospitalizations, and US\$800,000 in the city of São José dos Campos, with 1,900 hospitalizations ${ }^{\mathrm{a}}$, representing a public health problem.

The statistical techniques of logistic regression and Poisson's regression (Generalized Linear Models or Generalized Additive Models) are often used to estimate the chance or risk of hospitalization or death for respiratory diseases ${ }^{9}$.

A new form of epidemiological data analysis in public health is fuzzy logic. The fuzzy set theory was introduced by Lotfi A. Zadeh ${ }^{23}$, in 1965, and can work with the vague aspect of information particular to human understanding and very common in the medical field, in which descriptions of diseases often comprise language terms that are inevitably vague, such as fever (high or low) ${ }^{15}$. Unlike the classical set theory, in which an element belongs or does not belong to a set, in the theory of fuzzy sets an element may belong to more than one set with different degrees of relevance (varying between zero and one). These fuzzy sets are represented by the relevancy function, whose determination depends on the specialist's individual perception and the data at hand ${ }^{17}$.

The ability to deal with linguistic terms can explain the increase in the number of studies that use fuzzy logic in biomedicine problems. In fact, the fuzzy logic theory has become an important approach in diagnosis systems, prognosis, forecasting models, medical treatment and, more recently, in epidemiology and public health ${ }^{13,15,17,18,20,22,23,6}$.

This study's objective was to develop a computational model using fuzzy logic to estimate the influence of exposure to air pollutants in the number of hospital admissions for asthma and pneumonia.

\section{METHODS}

This is a computational model using fuzzy logic to estimate the number of hospitalizations for pneumonia and bronchial asthma per the concentrations of the pollutants particulate matter $\left(\mathrm{PM}_{10}\right)$, ozone $\left(\mathrm{O}_{3}\right)$ and sulfur dioxide $\left(\mathrm{SO}_{2}\right)$ and the apparent temperature (TEMPap), calculated by considering ambient temperature and relative air humidity².

a Ministério da Saúde (BR), Departamento de Informática do Sistema Único de Saúde Datasus. Brasília (DF); c2008 [cited 2012 Aug 12]. Available from: http://www2.datasus.gov. br/DATASUS/index.php

${ }^{b}$ Ortega NRS. Aplicação da Teoria dos Conjuntos Fuzzy a problemas de biomedicina [these]. São Paulo (SP): Instituto de Física da Universidade de São Paulo; 2001.
The environmental pollutants and climatic variables data in this study were obtained from the Environmental Company of the State of São Paulo (CETESB), which has a measuring station in the city of São José dos Campos. The data of the number of hospitalizations for pneumonia and bronchial asthma (ICD-10: J12 to J18 and J45) in individuals of all ages residing in São José dos Campos, in the period from 1/1/2007 to 12/31/2007, were obtained from the Department of Information and Computer Science of the Brazilian Unified Health System (DATASUS).

This study was carried out in São José dos Campos, a medium-sized city in the State of São Paulo, which has an important industrial park. It is located at $23^{\circ} 10^{\prime} \mathrm{S}$ and $45^{\circ} 52^{\prime} \mathrm{O}$, in the 
Alto Vale do Paraíba, $600 \mathrm{~m}$ above sea level, has wet weather and tropical altitude, located between São Paulo and Rio de Janeiro - the two largest cities in Brazil; is cut through by the Via Dutra, the most important highway in the country with heavy traffic of buses and trucks. Its population is estimated to be around 650,000 inhabitants.

The model was developed with the help of a specialist who created two functions of relevance for the input variables: $\mathrm{PM}_{10}$ - good and bad; $\mathrm{O}_{3}$ - good and bad; $\mathrm{SO}_{2}$ - good and bad; and TEMPap - good and bad. These fuzzy sets were drawn based on the data obtained from CETESB ${ }^{c}$.

The output variable was the number of hospitalizations for asthma and pneumonia and its five relevance functions we classified as follows: very low, low, medium, high and very high.

The fuzzy linguistic model is a rule-based inference system using fuzzy set theory to address the phenomenon. Its structure includes four components:

- The fuzzifier, which transforms real inputs (also known as crisp) into fuzzy values;

- The rule base, which defines the connection between the system's inputs and outputs. A fuzzy rule has the following form: if precedent, then consequent, in which the precedent can be composed of one or more fuzzy sets connected by fuzzy operators. And the consequent represents the fuzzy values of output variables;

- The inference system, which evaluates all rules, checks which have been activated (with degree of relevance greater than zero) and combines the resulting weights of all the rules enabled on a single output (in this study, we used the Mamdani's inference system); and

- The defuzzifier that performs the reverse process of the fuzzifier, that is, it transforms the fuzzy output into an actual value (crisp) ${ }^{21}$.

When performing the combination of all possible entries, it was possible to develop 16 rules resulting from the combination of the four entries with two functions of relevance each $(2 \times 2 \times 2 \times 2)$, drawn up with the aid of an expert. For example, two combinations could be:

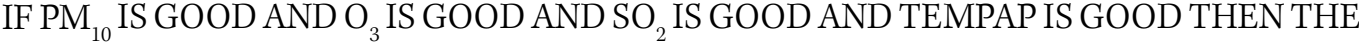 NUMBER OF HOSPITALIZATIONS IS VERY LOW}

\section{IF PM ${ }_{10}$ IS BAD AND O IS BAD AND SO $_{2}$ IS BAD AND TEMPAP IS BAD THEN THE NUMBER OF HOSPITALIZATIONS IS VERY HIGH}

The number of hospitalizations of the fuzzy linguistic model was determined by the inference method (fuzzy) proposed by Mamdani ${ }^{23}$, which consists in calculating the minimum (degrees of activation) of the rule's precedents and, subsequently, the aggregation of the rule's consequents (maximum operator). Finally, the defuzzification is performed, based on the area center method ${ }^{17}$.

Through a routine (toolbox fuzzy) that is part of the program MATLAB ${ }^{21}$, we obtained the numerical output resulting from the fuzzy model, providing the number of hospitalizations for each combination of the database entry. After obtaining the model's result, we performed a Pearson correlation with actual admissions data, using up to two days of lag (lag 2) because the display effect can manifest on the same day (lag 0 ) or on subsequent days. The accuracy, along with its 95\% confidence interval was estimated using the ROC curve. do Estado de São Paulo. Sistema Qualar. São Paulo; [cited 2017 Mar 20]. Available from: http:// Because the data are available on the network and cannot be identified, a submission to the Research Ethics Committee was unnecessary. 
¿ Ministério do Meio Ambiente (BR). Resolução Conama ${ }^{\circ}$ 003, de 28 de junho de 1990 Diario Oficial Uniao. 22 ago 1990 [cited 2012 Aug 10]; Seção 1:15937-9. Available from: http:// www.mma.gov.br/port/conama/ res/res90/res0390.html

\section{RESULTS}

In the period study, 1 January, 2007 to 31 December, 2007, 1,710 hospitalizations were recorded according to DATASUS .

Table 1 shows the mean value, standard deviation, the minimum and maximum value of the $\mathrm{PM}_{10}, \mathrm{O}_{3}, \mathrm{SO}_{2}$, TEMPap variables and the number of hospitalizations.

Twelve times ozone exceeded the value used by the National Council for the Environment (CONAMA $)^{\mathrm{d}}$. Particulate matter and sulfur dioxide did not exceed those limits.

Relevancy functions of input variables: $\mathrm{PM}_{10} ; \mathrm{O}_{3} ; \mathrm{SO}_{2}$ and TEMPap are shown in Figure 1 (A-D). The output variable: number of hospitalizations for asthma and pneumonia with its five relevancy functions are shown in Figure 2.

The results obtained by the ROC curve are presented in Table 2 . The best result was obtained for the zero-day lag (lag 0), $\mathrm{PM}_{10}$ and $\mathrm{SO}_{2}$ showed the best performance per the ROC curve, with statistically significant values.

Table 1. Values of the averages, standard deviation (SD), minimum and maximum of the variables particulate matter $\left(\mathrm{PM}_{10}\right)$, ozone $\left(\mathrm{O}_{3}\right)$, sulfur dioxide $\left(\mathrm{SO}_{2}\right)$, apparent temperature (TEMPap) and the number of hospitalizations (NINTER). São José dos Campos, State of São Paulo, Brazil, 2007.

\begin{tabular}{lcccc}
\hline Input/output variables & Average & SD & Minimum & Maximum \\
\hline $\mathrm{PM}_{10}\left(\mu \mathrm{g} / \mathrm{m}^{3}\right)$ & 26.0 & 11.3 & 8.0 & 89.0 \\
$\mathrm{O}_{3}\left(\mu \mathrm{g} / \mathrm{m}^{3}\right)$ & 91.0 & 67.9 & 17.0 & 162.0 \\
$\mathrm{SO}_{2}\left(\mu \mathrm{g} / \mathrm{m}^{3}\right)$ & 3.8 & 3.3 & 0.9 & 27.0 \\
$\mathrm{TEMPap}\left({ }^{\circ} \mathrm{C}\right)$ & 17.9 & 0.9 & 5.7 & 20.2 \\
NINTER & 4.9 & 2.9 & 0 & 16.0 \\
\hline
\end{tabular}
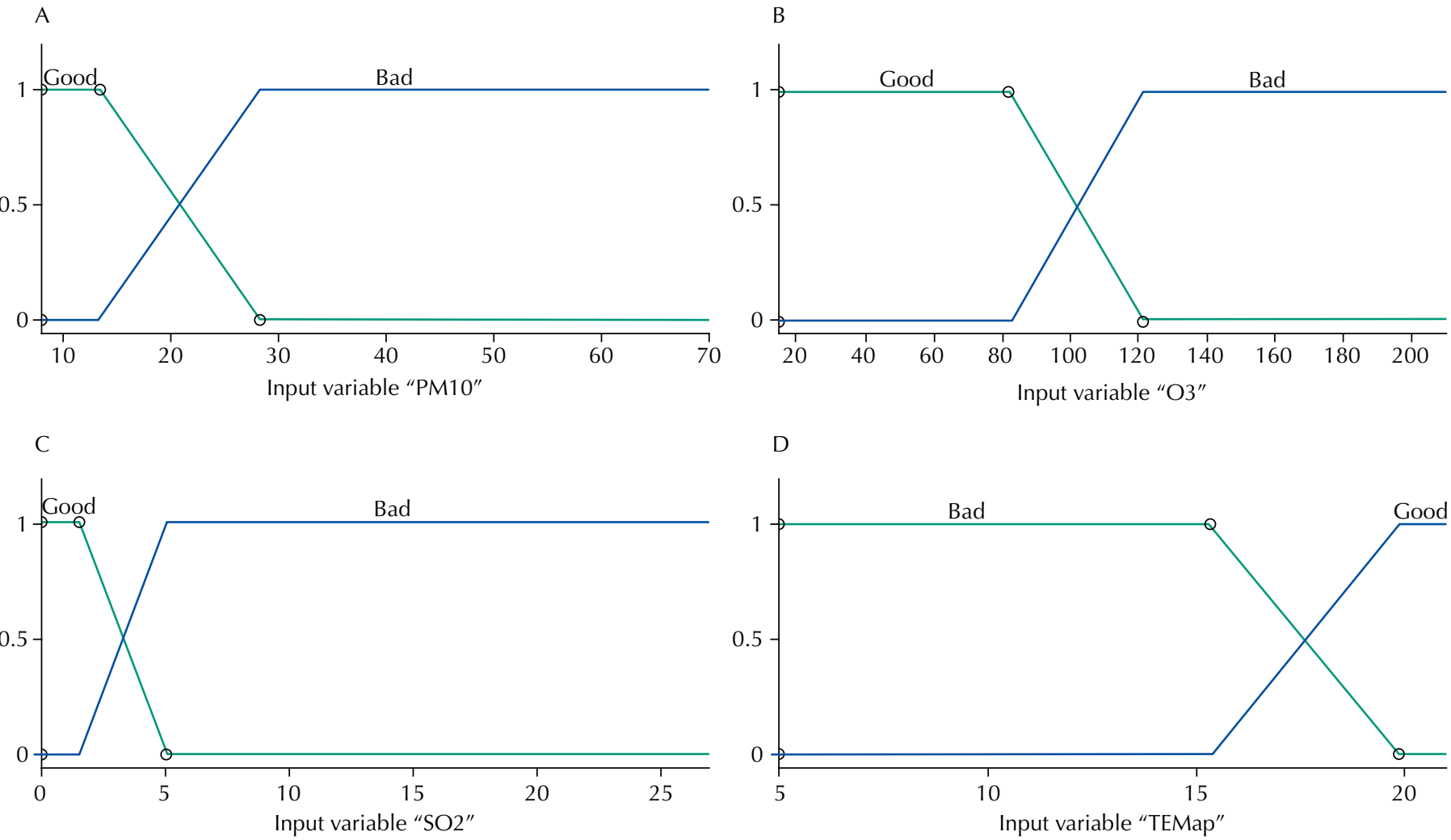

Figure 1. Input function of relevance: (A) Particulate matter $\left(\mathrm{PM}_{10}\right),(\mathrm{B})$ Ozone $\left(\mathrm{O}_{3}\right),(\mathrm{C})$ sulfur dioxide $\left(\mathrm{SO}_{2}\right)$ and $(\mathrm{D})$ apparent temperature (TEMPap), of the fuzzy model for estimation of the number of hospitalizations in the city of São José dos Campos, State of São Paulo, Brazil, 2007. 


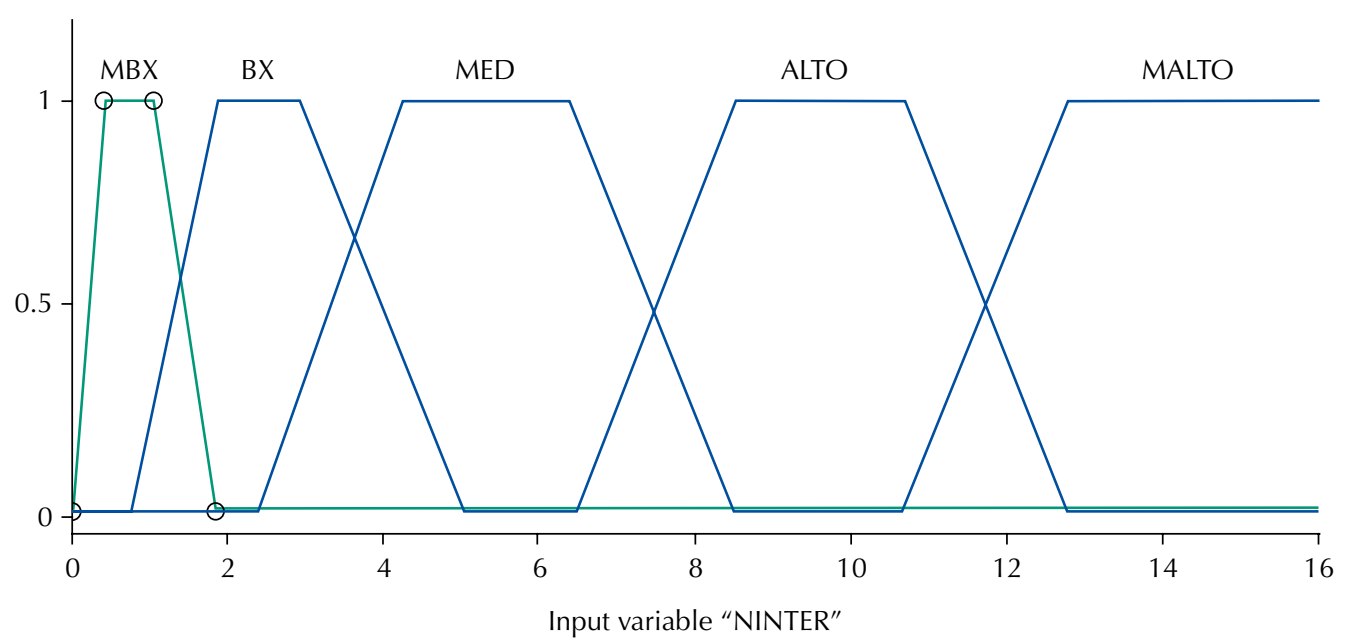

Figure 2. Output functions of relevance (number of hospitalizations) very low (MBX), low (BX), medium (MED), alto (ALTO) and very high (MALTO) for the fuzzy model in the city of São José dos Campos, State of São Paulo, Brazil, 2007.

Table 2. Roc curve values for lag 0, lag 1 and lag 2 of the pollutants $\mathrm{PM}_{10^{\prime}} \mathrm{O}_{3}$, and $\mathrm{SO}_{2}$, per output type, the number of hospitalizations up to 2. São José dos Campos, State of São Paulo, Brazil, 2007.

\begin{tabular}{lccc}
\hline Input variable & Lag $\mathbf{0}(\mathbf{9 5} \% \mathrm{Cl})$ & Lag $\mathbf{1}(\mathbf{9 5} \% \mathrm{Cl})$ & $\operatorname{Lag} \mathbf{2}(\mathbf{9 5} \% \mathrm{Cl})$ \\
\hline $\mathrm{PM}_{10}$ & $0.92(0.88-0.96)$ & $0.75(0.64-0.85)$ & $0.71(0.60-0.81)$ \\
$\mathrm{O}_{3}$ & $0.87(0.82-0.92)$ & $0.64(0.52-0.76)$ & $0.62(0.51-0.73)$ \\
$\mathrm{SO}_{2}$ & $0.95(0.92-0.97)$ & $0.73(0.63-0.82)$ & $0.79(0.72-0.87)$ \\
\hline
\end{tabular}

The Pearson correlation coefficient between the output of the fuzzy model and the actual data were 0.38 for lag 0 ; 0.36 for lag 1 and 0.30 for lag $2(\mathrm{p}<0.01)$; even though the values are not high, they were significant.

\section{DISCUSSION}

This article presents the development of a computational model using fuzzy logic to estimate the number of hospitalizations for asthma and pneumonia associated with air pollutants in a midsize industrial town. The results showed good accuracy when predicting the number of hospitalizations when exposure occurred on the same day and up to two days later. Additionally, we saw the acute effect the exposure to pollutants has in hospitalizations.

This study showed a maximum concentration of $\mathrm{PM}_{10}$ of $89 \mu \mathrm{g} / \mathrm{m}^{3}$, which is lower than the air quality advocated by $\mathrm{CETESB}^{\mathrm{c}}$, which is $120 \mu \mathrm{g} / \mathrm{m}^{3}$. According to CETESB, $\mathrm{PM}_{10}$ indexes between 51 and $100 \mu \mathrm{g} / \mathrm{m}^{3}$ classify an air of moderate quality and can cause symptoms such as a dry cough and fatigue in patients with respiratory diseases.

In the study by Arbex et al. ${ }^{2}, \mathrm{PM}_{10}$ may lead to airway irritation, inflammation, increased bronchial reactivity and decreased mucociliary activity, and its consequences are an increase in asthma attacks and respiratory infections.

In research conducted by Gouveia et al. ${ }^{12}$ in the city of São Paulo, State of São Paulo, $\mathrm{PM}_{10}$ presented an average of $54.5 \mu \mathrm{g} / \mathrm{m}^{3}$, a value well above this study's average, which was $26 \mu \mathrm{g} / \mathrm{m}^{3}$. We found that, with a $10 \mu \mathrm{g} / \mathrm{m}^{3}$ increase in the concentration of particulate matter, there was an increase of approximately $5 \%$ in the number of hospitalizations for asthma in children. Similarly, Nascimento et al. ${ }^{16}$ observed that, with an increase of $24.7 \mu \mathrm{g} / \mathrm{m}^{3}$ on the average concentration of $\mathrm{PM}_{10}$, there was an increase of $9.8 \%$ in 
hospitalizations for pneumonia in children in the city of São José dos Campos, with an average $\mathrm{PM}_{10}$ concentration of $40 \mu \mathrm{g} / \mathrm{m}^{3}$.

In the study performed with data from 2004 and 2005 in the same city ${ }^{1}$, the average was $25.2 \mu \mathrm{g} / \mathrm{m}^{3}$, a value close to the one found in this study, and hospitalizations for asthma were associated with exposure to $\mathrm{PM}^{10}$.

As for $\mathrm{O}_{3}$, the average value found in this study was o $91 \mu \mathrm{g} / \mathrm{m}^{3}$ for the period of 2007, close to the value found by Amâncio and Nascimento ${ }^{1}$ in São José dos Campos with an average of $74.3 \mu \mathrm{g} / \mathrm{m}^{3}$, by Gouveia et al. ${ }^{12}$, with an average of $71.8 \mu \mathrm{g} / \mathrm{m}^{3}$, and greater than the one observed by Negrisoli and Nascimento ${ }^{19}$, with an average of $37.1 \mu \mathrm{g} / \mathrm{m}^{3}$. On 12 days, the $\mathrm{O}_{3}$ exceeded the values of acceptable levels (up to $160 \mu \mathrm{g} / \mathrm{m}^{3}$ ) at CONAMA ${ }^{\mathrm{d}}$. In CETESB's ${ }^{\mathrm{c}}$ report, the inappropriate values for $\mathrm{O}_{3}$ are between $180 \mu \mathrm{g} / \mathrm{m}^{3}$ and $200 \mu \mathrm{g} / \mathrm{m}^{3}$ and can aggravate asthma symptoms in children with respiratory disease. In the general population, it can lead to the following symptoms: a dry cough, fatigue and burning sensation in the nose, throat, and eyes. The concentration of $\mathrm{O}_{3}$ had a significant growth in the last year in the city of São José dos Campos, per CETESB's latest report ${ }^{\mathrm{c}}$.

The concentration of $\mathrm{SO}_{2}$ had an average of $3.8 \mu \mathrm{g} / \mathrm{m}^{3}$, which is within the values tolerated by the World Health Organization (WHO), which accepts a maximum exposure level of up to $20 \mu \mathrm{g} / \mathrm{m}^{3}$ for 24 hours. This value was like the one found previously $\left(4.6 \mu \mathrm{g} / \mathrm{m}^{3}\right)$ in the same city ${ }^{1}$, with data collected between 2004 and 2005, and another study, also in São José dos Campos, averaging $6.2 \mu \mathrm{g} / \mathrm{m}^{3}$, with data from 2000 and $2001^{16}$.

In a research conducted in the city of São Paulo, Gouveia and Fletcher ${ }^{10}$ found an average concentration of $\mathrm{SO}_{2}$ of $17.71 \mu \mathrm{g} / \mathrm{m}^{3}$, which differs from the value found in this study. This difference can be explained by the larger fleet of vehicles in São Paulo, a major source of this pollutant.

The pollutants cited in this article and their magnitudes are described in national articles about this subject ${ }^{1-7}$ and it is important to note that the data of hospital admissions are related to hospitalization in the public health system. Even at concentrations considered safe, the pollutants can cause adverse health effects, especially on the cardiovascular and respiratory systems.

This study differs from other studies that estimate risks or chances of hospitalizations caused by exposure to air pollutants using logistic regression, retrospective studies or Poisson's regression ${ }^{1,3,5,6}$. In these models, fuzzy logic has the advantage of dealing with the uncertainty of information present in the meanings of words, facilitating dialogue between health care professionals and computational experts.

The fuzzy model showed itself to be very satisfactory by associating exposure to pollutants with the number of hospitalizations when compared with real outputs, with Pearson correlation coefficient of 0.38 . This methodology was used recently in the same city to analyze the average time of hospitalization arising from pneumonia ${ }^{18}$. In the national literature, there are also articles with fuzzy application in establishing the risk of neonatal death ${ }^{15,17}$ and neonatal resuscitation prediction ${ }^{20}$.

In epidemiological studies, it is common to find an association between the concentrations of air pollutants and the health effects on the next day, after two days or even after a week. Researchers generally adjust the model for different arrangements of the same database with lags. In time-series studies, lags of one to seven days are often used ${ }^{4,14}$.

The data obtained by the ROC curve of the model (Table 2) showed excellent accuracy and $\mathrm{PM}_{10}, \mathrm{O}_{3}$, and $\mathrm{SO}_{2}$ had a good performance with lag zero, which allows us to predict the effects of these pollutants on the same day that exposure occurs. The best result was for the pollutant $\mathrm{SO}_{2}$ at zero lag, with great accuracy and area under the curve of $95 \%$. Thus, we can conclude that the more $\mathrm{PM}_{10}$ and $\mathrm{SO}_{2}$ are present in the atmosphere, the more hospitalizations of patients with asthma and pneumonia will occur. 
The actual data regarding the number of hospitalizations ranged from zero to 16 and those obtained by the fuzzy model ranged from 0.7 to 13.9. This difference between minimum and maximum is due to the defuzzification method of the fuzzy inference system, in that the result is obtained by calculating the area center. Therefore, it would be mathematically difficult to obtain the area center around the ends of the universe of discourse of the output variable.

To improve the model, we can include more relevance functions in the input variables, which would involve a larger number of rules; or use different formats of relevance functions, such as Gaussian or triangular. The concentrations of pollutants are considered homogeneous for the implementation of this approach, which can be considered a limitation, since concentrations in other areas of the same city may differ from those recorded near the monitoring station.

This research is a low-cost financial tool and can be presented in a specific computer program (expert system) for this purpose, and does not require the opinion of experts. The model can be implemented in public health systems and can serve as an important instrument for prevention and decision-making regarding changes in the level of pollutants. It can also be applied in any locations where there are available data on pollutants and climatic conditions.

\section{REFERENCES}

1. Amâncio CT, Nascimento LFC. Asma e poluentes ambientais: um estudo de séries temporais. Rev Assoc Med Bras. 2012;58(3):302-7. https://doi.org/10.1590/s0104-42302012000300009.

2. Arbex MA, Cançado JED, Pereira LAA, Braga ALF, Saldiva PHN. Queima de biomassa e efeitos sobre a saúde. / Bras Pneumol. 2004;30(2):158-75. https://doi.org/10.1590/s1806-37132004000200015.

3. Arbex MA, Santos UP, Martins LC, Saldiva PHN, Pereira LAA, Braga ALF. A poluição do ar e o sistema respiratório. J Bras Pneumol. 2012;38(5):643-55. https://doi.org/10.1590/s1806-37132012000500015.

4. Bakonyi SMC, Danni-Oliveira IM, Martins LC, Braga ALF. Poluição atmosférica e doenças respiratórias em crianças na cidade de Curitiba, PR. Rev Saude Publica. 2004;38(5):695-700. https://doi.org/10.1590/s0034-89102004000500012.

5. Barnett AG, Tong S, Clements ACA. What measure of temperature is the best predictor of mortality? Environ Res. 2010:110(6):604-11. https://doi.org/10.1016/j.envres.2010.05.006.

6. Bueno FF, Fonseca AR, Braga FA, Miranda PSC. Qualidade do ar e internações por doenças respiratórias em crianças no município de Divinópolis, Estado de Minas Gerais. Acta Sci Health Sci. 2010;32(2):185-9. https://doi.org/10.4025/actascihealthsci.v32i2.7344.

7. Cançado JED, Braga A, Pereira LAA, Arbex MA, Saldiva PHN, Santos UP. Repercussões clínicas da exposição à poluição atmosférica. J Bras Pneumol. 2006;32 Suppl2:S5-11 . https://doi.org/10.1590/S1806-37132006000800003.

8. Carmo CN, Hacon S, Longo KM, Freitas S, Ignotti E, Ponce de Leon A, Artaxo P. Associação entre material particulado de queimadas e doenças respiratórias na região sul da Amazônia brasileira. Rev Panam Salud Publica. 2010;27(1):10-6. https://doi.org/10.1590/s1020-49892010000100002.

9. Duan Z, Han X, Bai Z, Yuan Y. Fine particulate air pollution an hospitalization for pneumonia: a case-crossover study in Shijiazhuang, China. Air Qual Atmos Health. 2016;9(7):1-11. https://doi.org/10.1007/s11869-015-0383-y.

10. Gouveia N, Fletcher T. Respiratory diseases in children and outdoor air pollution in São Paulo, Brazil: a time series analysis. Occup Environ Med. 2000;57(7):477-83. https://doi.org/10.1136/oem.57.7.477.

11. Gouveia N, Mendonça GAS, Ponce-de-Leon A, Correia JEM, Junger WL, Freitas $\mathrm{CU}$, et al. Poluição do ar e efeitos na saúde nas populações de duas grandes metrópoles brasileiras. Epidemiol Serv Saude. 2003;12(1):29-40. https://doi.org/10.5123/s1679-49742003000100004.

12. Gouveia N, Freitas CU, Martins LC, Marcílio IO. Hospitalizações por causas respiratórias e cardiovasculares associadas à contaminação atmosférica no município de São Paulo, Brasil. Cad Saude Publica. 2006;22(12):2669-77. https://doi.org/10.1590/S0102-311X2006001200016. 
13. Jensen R, Lopes MHBM, Silveira PSP, Ortega NRS. Desenvolvimento e avaliação de um software que verifica a acurácia diagnóstica. Rev EsC Enferm USP. 2012;46(1):184-91. https://doi.org/10.1590/S0080-62342012000100025.

14. Martins MCH, Fatigati FL, Véspoli TC, Martins LC, Pereira LAA, Martins MA, et al. Influence of socioeconomic conditions on air pollution adverse health in elderly people: an analysis of six regions in São Paulo, Brazil. J Epidemiol Community Health. 2004;58(1):41-6. https://doi.org/10.1136/jech.58.1.41.

15. Nascimento LFC, Ortega NRS. Fuzzy linguistic model for evaluating the risk of neonatal death. Rev Saude Publica. 2002;36(6):686-92. https://doi.org/10.1590/s0034-89102002000700005.

16. Nascimento LFC, Pereira LAA, Braga ALF, Módolo MCC, Carvalho Jr JA. Efeitos da poluição atmosférica na saúde infantil em São José dos Campos, SP. Rev Saude Publica. 2006;40(1):77-82. https://doi.org/10.1590/s0034-89102006000100013.

17. Nascimento LFC, Rizol PMSR, Abiuzi LB. Establishing the risk of neonatal mortality using a fuzzy predictive model. Cad Saude Publica. 2009;25(9):2043-52. https://doi.org/10.1590/s0102-311x2009000900018.

18. Nascimento LFC, Rizol PMSR, Peneluppi AP. Estimating the average length of hospitalization due to pneumonia: a fuzzy approach. Braz / Med Biol Res. 2014;47(11):977-81. https://doi.org/10.1590/1414-431×20143640.

19. Negrisoli J, Nascimento LFC. Atmospheric pollutants and hospital admissions due to pneumonia in children. Rev Paul Pediatr. 2013;31(4):501-6. https://doi.org/10.1590/s0103-05822013000400013.

20. Reis MAM, Ortega NRS, Silveira PSP. Fuzzy expert system in the prediction of neonatal resuscitation. Braz / Med Biol Res. 2004;37(5):755-64. https://doi.org/10.1590/s0100-879x2004000500018.

21. Sivanandam SN, Sumathi S, Deepa SN. Introduction to fuzzy logic using MATLAB. Berlin: Springer; 2007

22. Sousa CA, Duarte PS, Pereira JCR. Lógica fuzzy e regressão logística na decisão para prática de cintilografia das paratiróides. Rev Saude Publica. 2006;40(5):898-906. https://doi.org/10.1590/s0034-89102006000600021.

23. Zadeh LA. Fuzzy sets: information and control. New York: Academic Press; 1965. p.338-53.

Funding: Conselho Nacional de Desenvolvimento Científico e Tecnológico (CNPq - Productivity Scholarship for Research on Nascimento LFC - Process 308297/2011-3).

Authors' Contribution: All the authors contributed equally to this article.

Conflict of Interest: The authors declare no conflict of interest. 